TEI

JOURNAL OF THE TEXT ENCODING INITIATIVE

\section{Journal of the Text Encoding Initiative}

Issue 12 | July 2019 - May 2020

Selected Papers from the 2017 TEl Conference

\title{
TEI Pedagogy and TAPAS Classroom
}

Julia Flanders, Syd Bauman, Ashley Clark, Benjamin Love (Doyle), Scott Hamlin and William Quinn

\section{OpenEdition}

\section{Journals}

Electronic version

URL: http://journals.openedition.org/jtei/2144

DOI: $10.4000 /$ jtei.2144

ISSN: 2162-5603

\section{Publisher}

TEl Consortium

\section{Electronic reference}

Julia Flanders, Syd Bauman, Ashley Clark, Benjamin Love (Doyle), Scott Hamlin and William Quinn, "TEI Pedagogy and TAPAS Classroom », Journal of the Text Encoding Initiative [Online], Issue 12 | July 2019 - May 2020, Online since 14 August 2019, connection on 25 June 2020. URL : http:// journals.openedition.org/jtei/2144; DOI : https://doi.org/10.4000/jtei.2144

For this publication a Creative Commons Attribution 4.0 International license has been granted by the author(s) who retain full copyright. 


\section{TEI Pedagogy and TAPAS Classroom}

Julia Flanders, Syd Bauman, Ashley Clark, Benjamin Love (Doyle), Scott Hamlin, and William Quinn

\section{ABSTRACT}

This paper focuses on recent work by the TEI Archiving, Preservation, and Access Service (TAPAS) on pedagogy with TEI, and specifically on a recent initiative called "TAPAS Classroom" focused on exploring pedagogical uses of TEI. We provide some background on TAPAS, describe several case studies involving pedagogical partners who used TAPAS in teaching, and finally describe the TAPAS Classroom initiative and its outcomes.

INDEX

Keywords: pedagogy, TAPAS, XSLT, validation 


\section{Introduction and Background}

$1 \quad$ TAPAS $^{1}$ originated with the needs of humanities scholars and specifically with the rise (in the first decade of the twenty-first century) of scholarly interest in text encoding as a core humanities method. With expertise supported by the proliferation of text encoding workshops aimed at humanists, such scholars were typically not affiliated with large established projects but were often working independently on small, monograph- or article-scale projects, such as an edition of a single text, a small collection of manuscripts, or a small run of a local periodical. As already noted in a previous article (Flanders and Hamlin 2013), infrastructure for TEI publication was at that time (and still remains to some extent) challenging for individual scholars and small projects, because of the costs and logistics of maintaining servers, developing and supporting XSLT stylesheets, and maintaining technical expertise for troubleshooting and longer term support. TAPAS was developed to provide an alternative in the form of a web-based service for publishing TEI data. It offers a growing infrastructure of TEI publishing tools, a publishing venue that highlights the value of using TEI, and a long-term guarantee of visibility and access to the TEI data. TAPAS was originally hosted at Brown University and is now hosted at Northeastern University, which also provides a guarantee of long-term repository support for TAPAS data. TAPAS has been generously funded by the TEI Consortium and by an initial planning grant from the Institute for Museum and Library Services, a digital humanities startup grant from the NEH, a research and development grant from the NEH, and most recently a digital humanities advancement grant which has supported TAPAS Classroom.

\section{TAPAS Classroom and TEI Pedagogy}

What do we envision when we think of TEI "in the classroom"? Three scenarios are particularly prominent. The first involves students contributing to TEI projects. Many faculty who lead TEI projects seek to involve students in those projects, either as part of a formal course or workshop, or through internships or paid positions. Here the term "classroom" may be quite literal, but it also may entail a broader range of pedagogical activities whereby students learn on the job. For the students, learning TEI may be an important and useful outcome (if they are interested in working on TEI projects or pursuing a TEI project of their own), but it may also be just one piece 
of a larger learning experience centering around the creation, management, and publication of digital materials. A second scenario involves students experimenting with TEI encoding in (digital) humanities courses or short workshops which aim to introduce them to the concepts of text markup. Here, TEI may be most valuable as an approachable form of data modeling that uses familiar concepts and terminology, and that usefully demonstrates the separation of data modeling from data presentation. In these situations, the goal is not to create high-quality TEI files or to give the students a thorough grounding in the TEI vocabulary but rather to stimulate thought and discussion using TEI as a stimulus. A third scenario involves students creating their own TEI projects in digital humanities courses or humanities courses, often as a substantial assignment in which the student selects, transcribes, encodes, and contextualizes one or more texts. Here, even though TEI skills may be only one part of a larger goal of acquainting students with digital humanities project planning and publishing tools, the sustained nature of the undertaking means that students will have an opportunity to gain familiarity with TEI, and that they may produce TEI data of enduring value. Table 1 summarizes the potential learning outcomes in each of these scenarios.

Table 1. Learning outcomes.

\begin{tabular}{|c|c|c|c|c|}
\hline & $\begin{array}{l}\text { Learning } \\
\text { general data } \\
\text { concepts }\end{array}$ & $\begin{array}{l}\text { Learning TEI } \\
\text { vocabulary }\end{array}$ & $\begin{array}{l}\text { Learning TEI } \\
\text { practices } \\
\text { and context }\end{array}$ & $\begin{array}{l}\text { Create } \\
\text { TEI data } \\
\text { of value }\end{array}$ \\
\hline $\begin{array}{l}\text { Contribute to } \\
\text { existing project }\end{array}$ & Yes & Yes & Maybe & Yes \\
\hline $\begin{array}{c}\text { Experiment } \\
\text { with TEI in } \\
\text { DH classroom }\end{array}$ & Yes & Maybe & No & No \\
\hline $\begin{array}{c}\text { Develop } \\
\text { own project }\end{array}$ & Yes & Yes & Maybe & Maybe \\
\hline
\end{tabular}


During the development of TAPAS Classroom, several scholars were already experimenting with using TAPAS pedagogically. The following case studies describe how these different scenarios played out in practice.

\subsection{Scenario 1: A Course Designed Around Student Participation in a Faculty Research Project.}

Karen Bourrier, Digital Dinah Craik (http://www.tapasproject.org/node/443)

4 Karen Bourrier is a faculty member at the University of Calgary and has been using TAPAS for her project, Digital Dinah Craik; a presentation at TEI 2017 by her research assistant and project editor Kailey Fukushima described the project's work in detail. This project includes close to four hundred TEI files organized into six distinct collections. The project team includes a rotating group of undergraduate and graduate students who typically have no TEI experience when they start work, and who transcribe, encode, and add enhanced markup to each text as it proceeds through the project's workflow. They are trained to encode in TEI/XML (using the Oxygen XML editor) and to use TAPAS once a completed text is ready to publish. Professor Bourrier's pedagogical objectives for the course include professionalization of students through involvement in long-term digital projects, and engaging students in collaborative relationships with faculty and scholars in their field. (Kailey Fukushima reported that TAPAS publication constituted a useful addition to students' CVs.) Practically speaking, because of the students' lack of prior experience with TEI, it was important to have easy-to-use tools so that students could focus on concepts and gain fluency, thereby streamlining the process of training students to work on the project.

5 Professor Bourrier's pedagogical experimentation with TAPAS yielded several specific design considerations. First, a close linkage between process and outcome is valuable in motivating students and focusing their effort, so a workflow that permits immediate publication (and in which the concept of "publication" and the criteria for readiness are in the control of the instructor) has pedagogical value. Second, to support work in collaborative teams the publishing platform has a role to play in reinforcing the students' sense of working as a team, through actions like sharing and reviewing draft work, being able to track progress towards a final publication goal, and being able to communicate with other team members through comments and discussion. 


\subsection{Scenario 2: Student Experimentation with TEl as Part of a Larger Digital} Humanities Course

Mackenzie Brooks, Washington and Lee University (DH 190 Scholarly Text Encoding (winter 2015) http://www.tapasproject.org/node/439 with schedule at http://tei.academic.wlu.edu/dh-190w15/schedule/; and DH 190 Scholarly Text Encoding (winter 2016) http://www.tapasproject.org/ dh-190-scholarly-text-encoding-w16 with schedule at http://tei.academic.wlu.edu/dh-190-w15/ schedule/)

7 Mackenzie Brooks is an assistant professor and digital humanities librarian at Washington and Lee University, who used TAPAS in two iterations of a one-credit "lab" course on scholarly text encoding with TEI, accompanying a course in French literature taught by Professor Stephen P. McCormick. The course covered the origins and theoretical orientations of text markup, document analysis, schema creation, encoding, and publication, and also provided students with a grounding in the technical skills necessary to create a digital edition as part of the work they were doing in the accompanying literature class. Working in groups, students created simple digital editions focused on a specific text drawn from the university's rare book and manuscript collection.

8 As Brooks reported in a paper that described this course in detail (Brooks 2017), digital humanities at Washington and Lee University has a strongly pedagogical focus, and this course was an experimental contribution to a discussion of what a DH course or indeed an entire DH curriculum might look like. Framing the digital component as a one-credit "lab" course, taught by library faculty, offered a way to integrate digital approaches more flexibly into the curriculum without creating a burden for disciplinary faculty. In this context, a platform like TAPAS enables the instructors to focus on the challenges of teaching text encoding and to reduce the technical overhead for both students and instructors so that questions relating to editorial theory and practice and literary interpretation can come to the fore.

9 Constance Crompton and Michelle Levy, Simon Fraser University (Lyrical Ballads, https:// lyricalballadssfu.wordpress.com/).

Connie Crompton is a faculty member at the University of Ottawa (at the time of the course, she was at UBC Okanagan). She worked with a course that was taught by Michelle Levy at Simon Fraser University and focused on creating a digital edition of Wordsworth's and Coleridge's Lyrical Ballads. In this case, all of the students collaborated on a single edition rather than working on 
their own. TAPAS was one of a range of tools the class experimented with, along with visualization tools like Tableau, publication tools like Islandora, and text analysis with R. Part of the design of the course was thus to experiment with the encoded TEI data through a plurality of tools and to produce a plurality of outcomes. This pedagogical orientation reinforces one of the core tenets (and challenges) of TAPAS's design, which is to avoid creating orthodoxies in TEI encoding arising from display outcomes that appear authoritative. The diversification of view packages in TAPAS, and TAPAS's role as one of many possible venues for publishing and displaying TEI data, can help encourage students of TEI to focus on the informational strength of their encoding rather than solely on the appearance of the output. Mary Isbell, University of New Haven, Digital Editing Projects (Spring 2016; materials are private) Mary Isbell is a faculty member at the University of New Haven, where she has been experimenting with building a program of digital humanities pedagogy using TEI. In spring 2016 she taught a course on Digital Editing, in which her ten undergraduate students created individual digital TEI editions which were published in TAPAS as a private collection visible only to members of the project. The course was aimed at English majors with no encoding background, with a central learning goal of developing students' skill in XML and TEI. It also attracted students from History and Communications. Here, as with Brooks's course described above, having students create individual editions of their own design was an important focus and was closely aligned with the technical and conceptual skill of modeling textual data through text encoding. Treating the encoding process as a scholarly activity rather than a simple textual exercise aligns with core principles of digital humanities pedagogy articulated in articles such as "A Tale of Two Internships: Developing Digital Skills Through Engaged Scholarship" (Hswe et al. 2017), and also serves to empower students as both tool-users and creators of cultural meaning. Isbell noted that the ability to see their work realized as a readable edition was a crucial motivator for students in pushing through the process of learning and debugging their TEI/XML encoding. Because TAPAS was in beta when Isbell ran the course, she resourcefully integrated bug discovery and reporting explicitly into the course, so that students had some exposure to the processes of digital humanities tool development and had a sense of participation in that process-an unintended but very positive outcome. 


\title{
2.3 Scenario 3: TEI Pedagogy as Part of a Student-Led Project
}

\author{
Africa, http://www.tapasproject.org/missionary-linguistics/missionary-linguistics, http://
} corpus-missionnaire.bc.edu, https://library.bc.edu/newsletter/?p=28

14 Calhoun with support from Anna Kijas, the Senior Digital Scholarship Librarian at Boston College. For this project, Calhoun encoded a proof-of-concept segment of a nineteenth-century dictionary, together with proof-of-concept authority lists for persons, organizations, and historical places. TAPAS served as the data repository for the encoded files, which were also published through a project web site that included an interactive map using CartoDB. ${ }^{2}$ In addition to the outcomes for Calhoun's own degree program and professional development, Kijas had some larger pedagogical objectives from the perspective of her digital humanities center: to involve non-faculty (library and DH center staff) in student teaching and student research, at both undergraduate and graduate level, and to introduce and support TEI as part of an institution-level initiative.

Although supporting student-led research was not on the TAPAS project's radar as a very likely usage scenario during the initial planning and design process for TAPAS Classroom, it is an important outcome that underscores the potential benefits of having access to TAPAS at the institutional level (i.e., as a benefit of TEI institutional membership). From the perspective of the library, one important feature of the TAPAS service is that it provides a low-cost but durable infrastructure easy for novices to master. From the perspective of the student researcher, the important features are the longevity and stability of the data (enabling continuity of the project through successive institutional moves) as well as ease of use.

\section{Goals and Desiderata}

Based on these experiments, the TAPAS development team set several important design goals for the TAPAS Classroom project, in supporting pedagogy with TEI: 
- Make the process easier: For faculty who teach with TEI (either for its own sake or as part of a larger course in digital humanities or humanities), some supporting infrastructure is needed. TAPAS can ideally streamline or eliminate the process of getting access to shared server space, setting up student accounts, and ensuring that data is stored safely and can be accessed after the course is over. These functions are valuable for instructors at all levels of technical expertise but are particularly enabling for instructors familiar with TEI but not with its supporting technologies (XSLT, XML databases, web publishing frameworks).

- Expose and demystify: The tool experimentation we saw in the Lyrical Ballads course and in Mary Isbell's Digital Editing course suggested the value of a publication system that makes it possible to see the publication apparatus as such, and to look under the surface: for instance by offering different stylesheets and viewing options and showing that the formatted display of TEI is independent of the underlying encoding. TAPAS can offer a multiplicity of viewing options and an interface that makes it easy to move between them, enabling students to make direct comparisons between different ways of handling the data and offering a clear causal view in which changes to the data have a visible effect on the output (thereby motivating students to experiment with the markup in greater detail).

- Support the encoding: In these scenarios, TAPAS was used as an end-point and a publication venue, but it is clear that there is pedagogical value in user-friendly TEI tools earlier in the classroom narrative as well. Mary Isbell, for instance, noted the potential value of student-level error messages, and Karen Bourrier observed how students learned from their encounter with the workflow management aspects of TAPAS. Through user-friendly validation, interactive ways to inspect the TEI encoding, and other ways for students to explore their encoding in progress from many perspectives, TAPAS has potential value as a source of approachable information that can inform the encoding process.

Under TAPAS Classroom, several major new pieces of TAPAS were developed that respond to these desiderata. First, we developed new stylesheets for viewing TEI files, aimed specifically at pedagogical uses; this grant also gave us an opportunity to develop a fully modular system for managing these "view packages" (about which more below). Second, we re-examined the ways in which validation functions in TAPAS, and began developing tools that present validation to 
students in a specifically pedagogical context rather than as part of TAPAS's own data management systems. Third, we developed a set of sample and template files to serve as starting points for students, recognizing that in short courses where the goal is to get students quickly oriented in a new skill (as for instance in the Crompton example described above), it could be helpful to have some pre-established starting points that are well contextualized and self-explanatory. And finally, we developed a "community workshops" space within TAPAS that simplifies the process of setting up a teaching environment, aimed particularly at instructors teaching shorter workshops that may be repeated over time. In what follows, we focus on two components in particular: the view packages and our initial forays into thinking about validation.

\section{View Packages}

17 The display of TEI files through the TAPAS interface is handled-as with almost all modern web display of TEI data-through XSLT stylesheets, and indeed one of TAPAS's most important functions is to enable users to transform and view their TEI data without having to write or run XSLT on their own. TAPAS'S XSLT stylesheets do not operate in isolation but as part of a more complex "view package" that includes several distinct components:

- One or more XSLT stylesheets which transform the source TEI data into another format (typically XHTML but potentially JSON or other formats that are particularly suited to some viewing application)

- A CSS stylesheet that provides styling information

- Optional JavaScript code to produce features of user interactivity (such as mouse-overs or selection of specific viewing options)

- Optional XProc code which handles the sequential processing of the data by the individual components of the view package

- Optional RELAX NG or ISO Schematron files that formalize any specific data constraints required by the view package (for instance, a view package for displaying a bibliography might include a test to ascertain that the file contains a $<$ listBibl>)

- Metadata about the view package that supports its use within the TAPAS system

- $\quad$ Supporting documentation of the view package, including a manifest that describes its components and the expectations concerning the kinds of data for which it is best suited 
Typically, each view package is oriented around a specific usage scenario, user community, or type of data, and offers some options for user choices and configuration that are appropriate for that scenario. For instance, a view package might focus on the display of heavily revised manuscripts and might offer readers the ability to view successive revision stages or choose which revisers' work to make visible. (This interface is not currently available in TAPAS but would be a great future project.) In this way, view packages serve as reading environments rather than as individual stylesheets, and they enable TAPAS to group together multiple viewing options that complement one another within a specific usage scenario, such as the ability to alternate between a normalized and a diplomatic view of a manuscript source. All view packages are maintained on GitHub, and a future goal for TAPAS is to use GitHub as a collaborative tool-enabling community members to propose and develop new view packages for inclusion in TAPAS.

18 From the user perspective, TAPAS contributors can specify a default view package for a given record or collection, so that when a reader visits that material their initial view of the TEI data reflects the contributor's choice. For instance, the creator of a collection of historic letters (such as the Digital Mitford project) might choose a view package that handles manuscript features well, while the creator of a teaching collection aimed at sparking discussion of XML visualization might instead choose the Hieractivity view package (described below) as the default. However, whatever the default setting is, TAPAS readers can select any view package option in the reading interface (even if it goes against the grain of the data), and this may offer readers additional insight into the TEI data that is shared via TAPAS.

\subsection{TAPAS Generic View Package}

The basic goal of the TAPAS Generic view package is to handle almost any TEI markup in a moderately functional way. It is not intended as a high-function or specialized display; the term "generic" signals the fact that it displays TEI data in a general-purpose manner and can serve as the default stylesheet for almost any kind of data for which no more specialized viewing option has been provided. It offers a good basic reading interface, with a table of contents for navigation and the ability to shift between diplomatic and normalized views. For pedagogical purposes, it has the virtue that it is very forgiving: it does not require or assume adherence to any specific TEI 
schema or encoding protocol, and it produces a visible outcome from a wide variety of encoding features (so that any class involving TEI is likely to generate something that will get results). Its display options give emphasis to the areas of TEI encoding that see most frequent pedagogical use: personography and contextual information, transcription of primary source documents, and basic display of prose narratives such as fiction, life writing, and letters. It also supports renditional encoding (on @rend or @style) so that student encoders can exert some influence on the output. Instructors have also noted that it works well as a proofreading display to reveal both encoding errors and transcription errors.

\subsection{Hieractivity View Package}

The Hieractivity view package was designed to offer a structural view rather than a textual view of a TEI document: that is, a view that emphasizes a reading of the markup rather than of the document itself. The view is zoomable so that a reader can view the document as if from a great distance to see its overall patterns, or up close to inspect particular features, and individual elements can be opened or collapsed. Similarly, the text can be "zoomed" from full visibility to invisibility. The package also works as a space for interactive inspection, offering the reader the ability to select specific elements for highlighting (from a list generated by the encoding in the document) and learn more about their frequency, distribution, and usage. Hieractivity is intended to stimulate students' thinking about markup, focusing attention on how encoding reflects and enacts genre, and foregrounding the level of encoding detail and the presence of specific markup features. In a classroom setting, this view package can be used to compare the encoding of different texts and to highlight the differences and similarities between different students' markup of the same text, between the structure of different texts, and between the encoding of different areas of the same text. The color highlighting and zoomability makes it easy to see patterns of comparison without having to interpret the TEI markup itself. Clicking on specific document structures produces a gloss on the markup being inspected, so that students can quickly see what markup was used in specific cases. This view can also serve as a report or rudimentary diagnostic of the markup in the text. 


\subsection{Other View Packages}

21 TAPAS currently also offers two other view packages: an XML view package which shows the XML code and a view that uses the open-source TEI Boilerplate stylesheets. ${ }^{3}$ The XML view is not remarkable in itself, but it is pedagogically useful within the overall ecology of the view packages because it allows students to see the direct connection between the markup and the different outcomes in the other view packages. It is also helpful for troubleshooting and for comparing results with other students. The TEI Boilerplate view package was originally included because it offered an easy-to-install viewing option early in the TAPAS development process, but it has shown its value in other ways as well: it offers several proof-of-concept viewing options that help demonstrate the versatility of display through simple changes in CSS, and in the future it might offer a way for TAPAS to accommodate user-contributed CSS and control over document display by that means. It also connects TAPAS to other strands of research and development for TEI publication.

\section{Validation}

22 Validation was a key outcome for TAPAS Classroom and proved more challenging than we anticipated, for reasons that have to do with the way TAPAS data is ingested into the Fedora repository component and how it is handled once ingested. There are three basic functions validation can potentially play in TAPAS:

- To test files upon ingestion to ensure they are XML documents, and specifically, TEI; this is a gatekeeping function with a simple yes or no answer. TAPAS currently uses validation in this way. 
- To provide users with a more detailed profile of their data once it gets into TAPAS. This function would go beyond the simple gatekeeping function to give users information about where their TEI data matches or fails to match a given schema. The first step in this detailed profiling would be to provide a more detailed validation report based on validation against the TAPAS schema (currently tei_all), but a further (and extremely valuable) step would be to support this with more detailed validation reporting against user-supplied schemas. TAPAS is currently developing a validation reporting feature, described in more detail below.

- To test a given file or set of files against a specific functional scenario. For instance, in the context of TAPAS view packages, validation could be used to discover and report on whether a given TEI file will work appropriately within a given view package, and if not, what is missing from the encoding.

For pedagogical purposes, validation serves a very specific set of needs. First, it can give students information about their own encoding (for example in the context of an assignment prompt) and can reinforce what students are learning about TEI by providing immediate feedback on the semantics and usage of specific elements. It can also support an instructor in evaluating and providing feedback on student work, by highlighting encoding errors (and potentially inconsistencies as well, depending on the validation approach). And it can be a useful stimulus to an in-class discussion of encoding, through comparison of different encoding approaches in relation to the stipulations of the standard. In all of these cases, the validation process raises a pedagogically valuable set of questions about the relationship-involving epistemological power, authority, and social consensus-between a schema and the documents students create. In some pedagogical settings, the schema may be accorded the status of a standard to be achieved, while in others it may function in more complex and dialogic ways as a hypothesis about texts to be tested and revised.

23 To support these pedagogical functions, TAPAS plans to treat validation in a somewhat novel way, using the view package technology to situate validation as a "view" of the document itself through the lens of a schema. Technically, the process involves:

- $\quad$ running a validation process in XProc 
- $\quad$ running an XSLT stylesheet that integrates the validation output with the TEI document

- $\quad$ running an XSLT stylesheet that transforms the whole thing into HTML for display (with JavaScript as needed to support interaction such as navigation between the error report and the document itself).

Along the way, the process substitutes error messages that are more intelligible to novices and also more reassuring and detailed, and collapses multiple occurrences of a given error message into a single instance. The result is to position the validation view less as an authoritative and fearsome report of failure and more as an informational report that describes the relationship between the document and the schema that has been invoked. An initial version of the validation view package was developed for TAPAS Classroom and is scheduled for release in 2020.

\section{Conclusion}

Pedagogical uses of TEI pose varied and distinctive requirements which depend on the role TEI plays in a particular classroom setting. In some cases, the goal may be to learn TEI and to excite students about its potential as a digital humanities tool. In other cases, the goal may be to use TEI as a way of framing a conversation about digital editing, data modeling, or data visualization. TAPAS (and the features developed through the TAPAS Classroom project) offers a platform for TEI display and publication that allows the complexities of TEI encoding to take a back seat-through encoding templates and a simple upload and publication workflow-in cases where expertise in TEI is not the main goal of the class. But at the same time, it offers the ability to look beneath the surface of those systems at any time, to gain greater insight into the encoding, and to explore what happens if the code or the display choices are changed. TAPAS also supports varied roles for students that give them different forms of scaffolded authority: as contributors to real-world publications, as creators of their own projects, as collaborators and experimenters in public spaces. TAPAS thus supports a vision of digital humanities pedagogy that is experiential, experimental, and collaborative. 


\section{BIBLIOGRAPHY}

Brooks, MacKenzie. 2017. “Teaching TEI to Undergraduates: A Case Study in Digital Humanities Curriculum.” College and Undergraduate Libraries 24:467-481. https://doi.org/10.1080/10691316.2017.1326331; https:// repository.wlu.edu/handle/11021/33912.

Flanders, Julia, and Scott Hamlin. 2013. “TAPAS: Building a TEI Publishing and Repository Service.” Journal of the Text Encoding Initiative 5. http://journals.openedition.org/jtei/788; DOI: 10.4000/jtei.788.

Hswe, Patricia, et al. 2017. "A Tale of Two Internships: Developing Digital Skills Through Engaged Scholarship.” Digital Humanities Quarterly 11 (3). http://www.digitalhumanities.org/dhq/ $\mathrm{vol} / 11 / 3 / 000319 / 000319 . h t m l$.

Kijas, Anna. 2016. "Digital Scholarship Project: Missionary Linguistics in colonial Africa / Corpus de travaux linguistiques des missionnaires." Boston College Libraries Newsletter. https://library.bc.edu/newsletter/? $p=28$.

Walsh, John, and Grant Leyton Simpson. 2013. “TEI Boilerplate.” Journal of Digital Humanities 2 (3). http:// journalofdigitalhumanities.org/2-3/tei-boilerplate/.

\section{NOTES}

1 http://www.tapasproject.org.

2 For a more detailed account of the project, see Kijas (2016).

3 TEI Boilerplate: http://dcl.ils.indiana.edu/teibp/index.html. See Walsh and Simpson (2013).

\section{AUTHORS}

\section{JULIA FLANDERS}

Julia Flanders is a professor of the practice in English and the director of the Digital Scholarship Group in the Northeastern University Library. She also directs the Women Writers Project and serves as editor in chief of Digital Humanities Quarterly, an open-access, peer-reviewed online journal of digital humanities. She has served as chair of the TEI Consortium and as President of the Association for Computers and the Humanities. Her 
research interests focus on data modeling, textual scholarship, humanities data curation, and the politics of digital scholarly work. She is the co-editor, with Neil Fraistat, of The Cambridge Companion to Textual Scholarship, and is also the co-editor, with Fotis Jannidis, of The Shape of Data in Digital Humanities: Modeling Texts and Textbased Resources

\section{SYD BAUMAN}

Syd Bauman is the Senior XML Programmer/Analyst at the Northeastern University Digital Scholarship Group. Syd has been interested in descriptive markup since the mid-1980s, and in the TEI since he first thumbed through a copy of TEI P1.1 in 1990. He served as the North American Editor of the TEI from 2001 through 2007, and currently serves on the TEI Council.

\section{ASHLEY CLARK}

Ashley M. Clark is the XML Applications Developer for the Northeastern University Library's Digital Scholarship Group. She builds and maintains digital ecosystems for TEI-based projects, including TAPAS and the Women Writers Project.

\section{BENJAMIN LOVE (DOYLE)}

Benjamin J. Love (Doyle) is a PhD candidate in English at Northeastern University. His dissertation focuses on the intersections of human rights, extra-national subjectivity, and literature in the nineteenth-century Atlantic world.

\section{SCOTT HAMLIN}

Scott Hamlin is co-founder and co-Director of the TAPAS Project. He is also the Director of Educational Technology and Support Services in Information Technology at Stonehill College, where he oversees educational technology, media technology, and end user support. He has taught workshops on the use of TEI and TAPAS and regularly co-teaches digital humanities classes to undergraduates.

\section{WILLIAM QUINN}

William Quinn is a PhD Candidate in the English Department at Northeastern University. He worked as the TAPAS Project Coordinator and Liaison between 2017-2019. His research attends to the intersection of literary history, digital humanities, and periodical studies. 